This item was submitted to Loughborough's Research Repository by the author.

Items in Figshare are protected by copyright, with all rights reserved, unless otherwise indicated.

\title{
Reducing temporal tensions as a strategy to promote sustainable behaviours
}

\section{PLEASE CITE THE PUBLISHED VERSION}

http://dx.doi.org/10.1016/j.chb.2016.04.004

\section{PUBLISHER}

(C) Elsevier

\section{VERSION}

AM (Accepted Manuscript)

\section{PUBLISHER STATEMENT}

This work is made available according to the conditions of the Creative Commons Attribution-NonCommercialNoDerivatives 4.0 International (CC BY-NC-ND 4.0) licence. Full details of this licence are available at: https://creativecommons.org/licenses/by-nc-nd/4.0/

\section{LICENCE}

CC BY-NC-ND 4.0

\section{REPOSITORY RECORD}

Oliveira, Luis C.R., Val Mitchell, and Andrew May. 2019. "Reducing Temporal Tensions as a Strategy to Promote Sustainable Behaviours". figshare. https://hdl.handle.net/2134/21131. 


\title{
Reducing Temporal Tensions as a Strategy to Promote Sustainable Behaviours
}

\author{
Luis Oliveira (l.oliveira@warwick.ac.uk) \\ Val Mitchell (v.a.mitchell@lboro.ac.uk) \\ Andrew May (a.j.may@lboro.ac.uk)
}

\begin{abstract}
This research proposes that it is possible to deliberately reduce temporal tensions in order to promote energy saving behaviours. People may not dedicate enough time to planning their tasks that consume energy, rushing into them without much deliberation. They may also use more energy than necessary in an attempt to accelerate processes that seem to be taking too long, to reduce the boredom of waiting. Persuasive technology provided the tools to manipulate the perception of time and therefore elicit changes in the specific behaviours that result in unnecessary energy usage. Cooking tasks were used as the scenario to test behaviour change strategies delivered via a smartphone application. Results showed that these strategies facilitated the performance of sustainable behaviours. Participants reported that the app made (1) them more likely to follow the steps needed to use less energy, (2) the activity more enjoyable and (3) the time appear to pass more quickly compared to a control version.
\end{abstract}

\section{Keywords}

Temporal tensions; time perception manipulation; behaviour change; energy saving; persuasive technology; smartphone

\section{INTRODUCTION}

The potential of technological interventions to bring about sustainability has gained attention over the past few decades. This research field has diverse labels such as Sustainable Interaction Design (Blevis, 2007), Environmental HumanComputer Interaction (HCI) (Goodman, 2009), Sustainable HCI (DiSalvo, Sengers, \& Brynjarsdóttir, 2010; E. M. Huang, 2011; Silberman \& Tomlinson, 2010) or Information and Communication Technologies for Sustainability (ICT4S) (Hilty \& Lohmann, 2013). However, there is ongoing demand for increased research in the area, the development of new innovative strategies to motivate sustainable behaviours, and success evaluation (E. M. Huang, 2011; Silberman \& Tomlinson, 2010; Steg \& Vlek, 2009).

Human behaviours are generally complex and are determined by diverse factors such as demographic variables, personality characteristics, and situational and domain-specific factors related to the behaviour under investigation (Fishbein \& Ajzen, 2010). There is a large number of theories attempting to explain behaviours and to provide the mechanisms for change (R. Davis, Campbell, Hildon, Hobbs, \& Michie, 2014). An individual's attitudes, social norms and the level of control they have can partially explain the performance of behaviours (Fishbein \& Ajzen, 2010). Other theories include social learning and more individual aspects such as self-efficacy (Bandura, 2001). Studies intending to evaluate behaviour change may be more effective when starting from the identification of the specific behaviours to be changed and an examination of the main factors underlying this behaviour (Abrahamse, Steg, Vlek, \& Rothengatter, 2005). Upon identifying these determinants, the chosen theory should inform the adequate intervention methods to attempt to change the consequent behaviours.

Persuasive technology describes a field where computational systems induce transformation of either attitudes or behaviours (Oinas-Kukkonen \& Harjumaa, 2009; Oinas-Kukkonen, 2013). Persuasive technologies can be used to increase energy use awareness, change people's behaviour and motivate them to commit to more environmentally friendly actions (Fogg, 2003). There has already been substantial work performed on strategies that can be implemented to change individual behaviours towards energy conservation. Research often investigates the use of technology designed specifically to change people's attitudes and behaviours, and these studies report different levels of success in promoting energy conservation in various forms of domestic energy use, from heating (Wilson, Bhamra, \& Lilley, 2015) to cold appliances (Tang \& Bhamra, 2012). The design of products and services can influence how we behave and ultimately contribute to minimising the negative environmental impact of energy consumption (Lockton, Harrison, \& Stanton, 2010).

One of the reasons for people wasting energy is that they do not want to wait nor put effort into energy saving behaviours. Chetty and colleagues (2009) exemplify this with the classic example of how people use computers. Devices are frequently left on because they do not want to experience the frustration of long boot up times. Previous studies with individuals who act pro-environmentally indicate that "efforts to be environmentally responsible typically required significant dedication of time, attention, and other resources” (Woodruff, Hasbrouck, \& Augustin, 2008, p. 313).

Cooking activities present special challenges for time management, and they can affect energy use. One study found that when acting patiently, participants used the least energy to complete the preparation of a menu (DeMerchant, 1997). Users in a hurry generally exhibited the highest energy consumption due to pre-heating saucepans, using high heat and not matching the diameter of heat source and cookware. These examples of previous research indicate that unnecessary 
energy use is caused by the unwillingness of people to dedicate enough time or pay the required attention to an optimised procedure that could save energy. In addition, individuals may want to accelerate the activities, resulting in extra energy use.

\subsection{Temporal tensions}

A group of researchers in Finland (Oulasvirta, Tamminen, Roto, \& Kuorelahti, 2005; Tamminen, Oulasvirta, Toiskallio, \& Kankainen, 2004) observed the concept of temporal tensions and defined it as the psychological construct based on assessing the availability of temporal, mental, physical and social resources. Sometimes it is necessary to fit more actions into a given time frame. In other situations the relationship between time and action is stretched - for example when individuals are just anticipating outcomes that are imminent.

This research proposes that it might be possible to promote energy saving behaviours via the implementation of strategies to reduce temporal tensions. Having the right information on how to act efficiently may not be sufficient to motivate sustainable behaviours. Temporal tensions can make it more difficult for people to perform certain behaviours, especially those believed to increase time to complete tasks. Therefore, the introduction of an intervention that reduces temporal tensions appears to be one way to motivate sustainable behaviours. Designing systems that change the involvement of the individual with the tasks has the potential to alter the sense of duration, make time appear to pass quickly and consequently reduce temporal tensions during specific activities. To date, no studies were found investigating how manipulating time perceptions could ultimately promote sustainability.

\subsection{Perceptions of time and duration}

Humans have subjective mental timers that affect the focus on the passage of time, therefore events may be perceived as having shorter or longer duration than clock time (Zakay \& Block, 1997). This phenomenon is usually dependent on the density of the experience (Flaherty, 2000; Holubar, 1961). Having few acts in a timeframe will make the temporal distance appear relatively longer (Figure 1b), and people then perceive time to 'drag' or be prolonged. Conversely, a higher number of events between points in time indicates that the distance between these two points appears relatively shorter (Figure 1a), making time seemingly 'fly' or be accelerated (Lewis \& Weigert, 1981). It is common to say that 'a watched pot doesn't boil', in reference to the "situation in which there is the perception that time is passing slowly" (Flaherty, 2000, p. 149). Individuals notice that the time is passing through changes in the environment. In periods of waiting and boredom, there is the impression that time lasts longer than expected or usual: there is not much happening to fill the units of time. The notion of time can be more painfully vivid during expectation and when we have to endure delay (Fraisse, 1963).

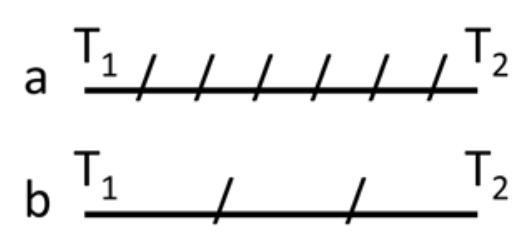

Figure 1 - Time and events (Lewis \& Weigert, 1981)

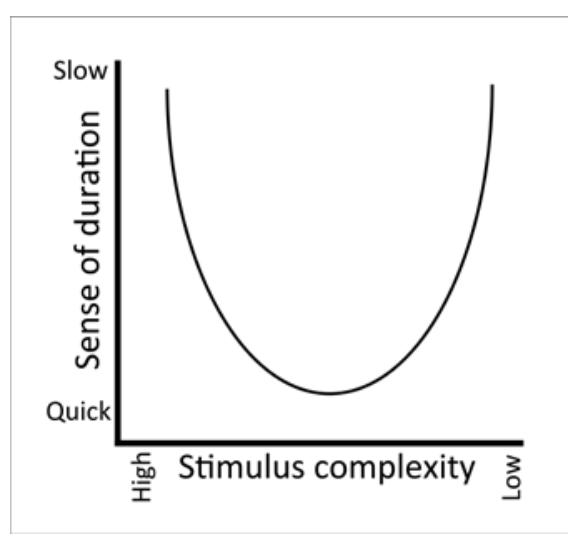

Figure 2 - Sense of duration of time versus stimulus complexity (based on Flaherty, 2000) 


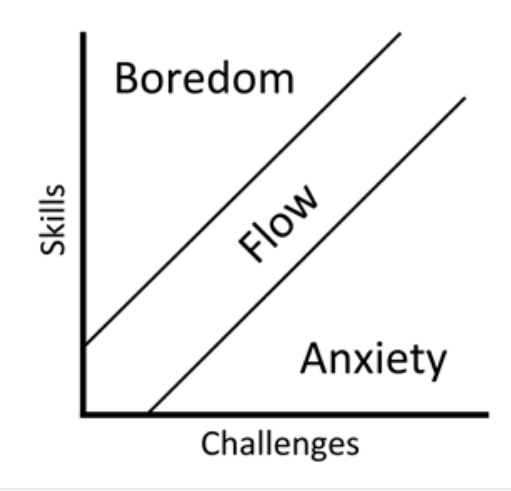

Figure 3 - Flow diagram (based on Csikszentmihalyi, 2000)

Figure 2 illustrates a paradox of time: Situations with extremely high stimulus complexity, such as those involving danger (a car crash, an assault) will demand high attention to self and situation, thus will be perceived as passing slowly. On the other extreme, situations with low stimulus complexity, such as when simply waiting during periods of boredom or when in stimulus depriving environments (empty waiting rooms, prisons) can also be perceived as passing slowly (Flaherty, 2000). Therefore, to make time appear to pass quickly, the situation must present neither high nor low stimulus complexity. Temporal compression can occur with low complexity of routines or habits involving low conscious deliberation. Between unusually slack times and extremely eventful circumstances sits the usual comfortable situation, when people experience routines and habitual times, which can make time pass relatively easily (Flaherty, 2000).

The optimal relationship between the challenges of the environment and one's skills determines an ideal state that is referred as Flow (Csikszentmihalyi, 2000). Figure 3 illustrates this optimal state, when an individual's skills match the challenges of the environment. However, if one's level of skill is high and there is not much challenge, this individual feels bored. If the challenges are higher and there are not enough skills to cope with these challenges, anxiety builds up. In a state of flow people's attention is entirely focused on the task at hand, they tend to lose track of time and start doing things spontaneously and automatically without having to think (Csikszentmihalyi, 2002). Flow theory is often used to develop and evaluate user experience when interacting with different forms of technology, from spreadsheets and emails to games (Novak, Hoffman, \& Yung, 2000; Pilke, 2004; Webster, Trevino, \& Ryan, 1993). Qualitative evaluations of the concept of flow in behaviour change support systems for health conditions have also been performed (Karppinen et al., 2014). Characteristics of flow include a distortion of temporal experience as people tend to lose track of time, and intense concentration when attention is invested in the present challenge - this explains how 'time flies when you are having fun'. Performing activities such as playing instruments, playing sports, dancing, playing chess or even working with something that requires a high level of concentration (such as surgery) can promote a state of flow, which brings enjoyment and satisfaction (Csikszentmihalyi, 2000).

The example of a restaurant kitchen illustrates a practical application of the theory of flow and temporal tensions. Chefs are usually skilled professionals who can manage the pressure of a fully booked restaurant. If running smoothly, busy schedules can be thoroughly enjoyable. In this situation, an individual's skills match the challenges of the environment. However, if challenges are higher than skills, or time shorter than needed to accomplish tasks, it increases the chances of mistakes and creates tensions. Fine (1990) observed tensions in the kitchen when cooks were short of time to prepare complex dishes. The challenges of the situation in terms of demands and time available made staff struggle, with chefs being "sarcastic to servers, and servers bothering cooks for their dishes. No one had the time to do things right, including being polite” (Fine, 1990, p. 104). In the opposite scenario, chefs became easily bored if the challenges of the restaurant were not demanding enough for their skills.

\subsection{Measuring and manipulating perceptions of time}

Researchers in HCI have increasingly focused on time perceptions over recent years (Kujala, Vogel, Pohlmeyer, \& Obrist, 2013; Lindley, Corish, Kosmack Vaara, Ferreira, \& Simbelis, 2013). Examples include understanding the user experience of time when using applications (C.-C. Huang \& Stolterman, 2011), experimenting with representations of time (Lundgren, 2013), and testing the satisfaction of feedback and perceptions of waiting time (Branaghan \& Sanchez, 2009; Harrison, Yeo, \& Hudson, 2010; Lallemand \& Gronier, 2012). Previous studies demonstrate that it is possible to deliberately customise temporal experiences with efforts to influence our own perceived duration, frequency, timing or allocation of time (Flaherty, 2003). It may also be possible to manipulate other people's perceptions of time, for example by encouraging absorption with attractive images (Gable \& Poole, 2012) or presenting filler interfaces during periods of wait (Lee, Chen, \& Ilie, 2012). Another study evaluated an active progress bar to make better use of waiting time, proposing samples of secondary activities to be performed below a typical progress bar (Hurter, Girouard, Riche, \& Plaisant, 2011). The distractions included entertainment or work activities, with the potential to help users make their 
time more productive while waiting. One study with progress indicators asked participants to rate linear bars, cycling bars and videos (Amer \& Johnson, 2014). Their results show that video progress indicators that draw the user's attention away from the passage of time were preferred, the duration of the process seemed to be shorter than with the other visualizations, and it promoted a better user experience.

These examples indicate that there is a body of research on ICT-based manipulation of time perceptions and reduction of temporal tensions. It is possible to improve interfaces and the user interaction to make the actual time taken to complete a process appears shorter than it really is (Seow, 2008). Technology can be used in such way that it "stretches time and slow things down” instead of only trying to make users perform their activities more quickly (Hallnäs \& Redström, 2001, p. 205).

\subsection{Cooking assistants}

A number of studies report the use of ICTs as assistants for cooking. These studies evaluate the role of technology in different aspects of the cooking activity, for example the attempt to increase users' confidence and fun when preparing unknown and complex recipes via a multi-display interactive system and a 'personal chef' (Mennicken, Karrer, Russell, \& Borchers, 2010). A cooking navigation system helps novice users to cook two dishes in parallel by optimizing time and processes, helped by text, video and audio from a touchscreen device (Hamada et al., 2005). Other research examines the use of HCI to overcome cognitive deficits via pervasive behaviour tracking and information (Giroux, Bauchet, Pigot, Lussier-Desrochers, \& Lachappelle, 2008). The panavi system integrates wireless sensors to measure temperature and pan movements, and this data feeds the system that displays the situated instructions, helping users to master culinary arts (Uriu et al., 2012). Cooking ideas is a system that can detect ingredients via RFID sensors and suggest recipes and procedures via an interactive tabletop (Lebrun, Lepreux, Haudegond, Kolski, \& Mandiau, 2014). MimiCook introduces a cooking support system that suggests a cooking procedure via augmented images projected over the tabletop, and the guidance changes to next steps in line with the user's progress (Sato, Watanabe, \& Rekimoto, 2014). Another study evaluates the Cook's Collage, a system that tries to prevent users losing track of the cooking progress by implementing a visual summary of on-going cooking activity, working as a memory aid during the process (Tran, Calcaterra, \& Mynatt, 2005). The SuChef system allows friends and family to share recipes and cook suggested dishes, working between geographically dispersed households (Palay \& Newman, 2009). An automated cabinet system assists the user in retrieving or storing items in the kitchen according to the recipe selected (Ficocelli \& Nejat, 2012). Another study evaluates the acceptance of different multimodal features of a cooking assistant depending on the context of use (Vildjiounaite et al., 2011). Studies at University of York (UK) investigated different options of electronic recipe presentations to understand cooks’ preferences (Buykx \& Petrie, 2011). Hupfeld and Rodden (2012) investigated food consumption in seven British households and reported how they organise domestic eating. Their objectives were to indicate the challenges involving the introduction of digital technologies to the table and to inspire digital innovations. They conclude that it is important to have a richer picture of food and eating in HCI in order to "make more informed choices about their digital augmentation” (Hupfeld \& Rodden, 2012, p. 127).

It is possible to find a number of studies on cooking assistants, their particular features' effectiveness or acceptance. However, the issue of energy consumption is seldom covered. In addition, people's relationships with time were not investigated before designing these applications. The systems exemplified here were designed and tested in an attempt to foster confidence, skills or knowledge, overcome cognitive deficits, mobility limitations or geographic barriers and improve interface features or recipe presentation. It is possible that by addressing these diverse issues the cooking assistants will have enhanced usability and present an improved user experience, and users will became more proficient and make fewer mistakes when cooking. Nevertheless, no studies were found on cooking assistants investigating energy consumption during the cooking activity, or addressing the boredom or anxiety that can happen during cooking. This represents an important gap in the literature since food preparation is often energy intense and user behaviours play an important role in energy consumption. Cooking demands several interactions between users and appliances, the user is in close proximity during operation, and there are numerous energy saving behaviours that can be performed during the cooking activity (Wood \& Newborough, 2007). There are also diverse techniques that the user can apply in order to reduce energy use, depending on the food prepared (Das et al., 2006; Oberascher, Stamminger, \& Pakula, 2011; Wade, Hinnells, \& Milne, 1995). A cooking assistant could be designed to promote sustainable cooking, and the strategy proposed here is to reduce temporal tensions through a persuasive application embedded in a mobile phone.

\subsection{Aims and research questions}

The aim of this research was to design and evaluate an intervention that brings modification of time perception as one of the strategies to promote sustainable behaviours. This paper applies the concept of temporal tensions in the domain of energy use, and it is hypothesised that by reducing these tensions it is possible to promote energy saving. A feasibility study was designed to evaluate strategies that attempt to manipulate time perceptions during activities using energy. These strategies were implemented in order to assess the reduction of temporal tensions and how it affects individual behaviours during the performance of a cooking task. A prototype of a smartphone application was used as the platform 
to evaluate how time perception manipulation can facilitate behaviour change and promote energy saving during cooking. The app ${ }^{1}$ was designed to help answer these two questions:

- Can an app make people take time in order to follow an efficient procedure? If people usually rush into cooking and skip steps important for energy saving, will the app make them take the time to perform these steps?

- Is it possible to make it easier for people to endure the recommended cooking time and not feel bored or anxious? If people normally want to hurry the process at a cost of extra energy use, will they be persuaded to let the food cook with the least energy input?

\section{METHODS}

This study used a within-subjects design, having 12 undergraduate students living in the UK as subjects taking part in two different experimentally manipulated conditions at different times. One phase (A) worked as control, or baseline, whilst the second (B) worked with the intervention, which was actively introduced with a view to producing a resultant change in individual behaviours. The trials consisted of a counter-balanced A-B / B-A design, with all 12 participants (8 males, 4 females, 18-22) experiencing both versions of the app. Four males and two females (picked at random) started using version $\mathrm{A}$ and later tested version $\mathrm{B}$, whereas the other four males and two females were asked to start with version $\mathrm{B}$ and used version A during their subsequent trial. This balancing was introduced to mitigate bias that could emerge from learnability and priming from one version to another. The two phases of the test were performed in two different days, usually on consecutive days.

Similarly to a previous study (Oliveira, Mitchell, \& Badni, 2012), students were asked to cook instant noodles using a solid plate electric cooker in a kitchen in their hall of residence (Figure 4). The utensils available were two different sized pans with their lids on the side, a measurement jug, wooden spoons, scissors, a bowl and a fork. The noodles were unpacked and placed on a plate together with the seasoning sachet to prevent participants using the packet instructions as source of information. A domestic energy monitor (The Owl) was used to record the electricity used during this experiment. This data was taken before and after each trial. Participants were not aware that their energy consumption was being monitored. At the beginning of each trial, students received a text message on their smartphones with a link to either of the versions of the app. At the end of the final trial participants were interviewed to share their impressions about both versions of the app. The experiment was video recorded and the audio of the interviews recorded, transcribed and subjected to thematic analysis.

\subsection{Evaluating acceptance and flow}

A survey was implemented in order to evaluate the app and the experience, from the users' point of view. All participants completed a 27-item questionnaire after both trials. The instrument was divided in two parts, tapping into the acceptance of technology and the engagement with the application. The first half of the survey used the widely used Technology Acceptance Model (F. D. Davis, 1989) to measure participants' perceptions of ease of use and usefulness. The statements were based on the scales proposed by Moore and Benbasat (1991), who tested the introduction of information technology innovation within organisations. Those statements not relevant to the cooking context were removed. The final selected constructs were:

- Relative advantage - to measure the usefulness of the app, or how the app enables the user to accomplish the task more quickly, improves the quality of food, makes it easier to cook, enhances the effectiveness during cooking or gives greater control over cooking

- Compatibility - To measure if the app is compatible with other aspects of cooking, if it fits well with the way participants like to cook

- Image - How participants rate those who use the app regarding prestige, and if the app is a status symbol or not

- Ease of use - to evaluate if the app is easy to use or if there is learning required

- Results demonstrability - if results of using the app are apparent, and if it is possible to communicate to others the consequences of using the app

The second part of the survey tapped into the temporal tensions of the cooking situation, the immersion, absorption and involvement with the app. The concept of flow comes from widely used propositions developed by Csikszentmihalyi $(2000,2002)$ and the constructs used on this instrument were based on a scale developed to measure the state of flow in computer game play (Fang, Zhang, \& Chan, 2013). Measurements not related to this research were removed. The remaining statements relevant to the cooking activity were the following:

- Concentration on the task at hand - to measure if the attention was focused entirely on the app and if the users were concentrating fully on what they were doing

\footnotetext{
${ }^{1}$ FlowCook, the prototype of the application used during this research is referred, for simplification, as the 'app', but it is in fact a mobile website built using JQuery Mobile libraries, JavaScript, HTML and CSS. Even though it looks and behaves like a native smartphone app, it was not installed on participant's devices.
} 
- The paradox of control - to determine if the users felt in control over what they were doing in the app and if they felt comfortable with the controls

- Immersion - to measure the loss of self-consciousness, the merging of action and awareness, the transformation of time

- Autotelic experience - to understand if using the app was rewarding in itself, and if participants enjoyed the experience

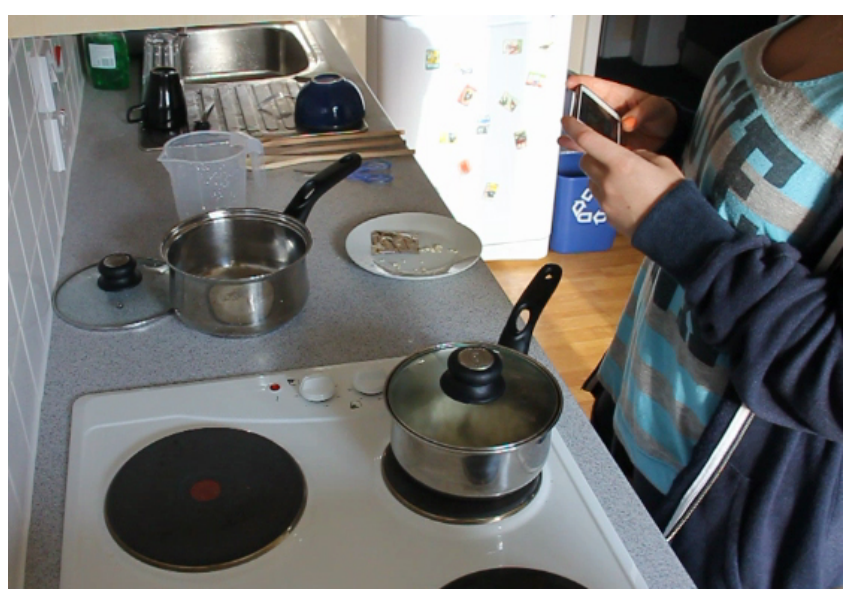

Figure 4 - The FlowCook app providing entertainment when waiting for the water to boil, during a user testing session

\subsection{Embedded strategies}

From prior formative research, the cooking activity was observed as having two main phases: preparation and waiting (Oliveira, Maguire, Mitchell, \& May, 2015). The first phase consists of the user preparing the utensils and ingredients to start cooking, and includes activities like unpacking the food, selecting the pan and hob, pouring the water and setting appliances ready to start the cooking process. In this stage, a careful selection of steps should be undertaken in order to achieve the best final results in terms of the quality of food, effort, time and energy use. Evidence from previous research showed that students rush into the cooking process without much consideration, failing to measure the amount of water, time the process, select the adequate hob and pan and cover the food (Oliveira et al., 2012). Even though habit, previous knowledge, preferences and other reasons may explain these behaviours, they inevitably resulted in extra energy use (Oliveira, Mitchell, \& Badni, 2011).

The second phase refers to the period when the user is waiting for food to be ready and mainly constitutes of stirring and waiting. When boiling noodles or similar food like pasta or rice, this stage involves minimum interaction with the food. There are few visual indications of change, as the characteristics of the food alter subtly and slowly. Consequently, there is no sensation of change in the environment, making time appear to pass slowly (Fraisse, 1963). Hence students were tempted to do something to alleviate the waiting boredom, usually at the cost of extra energy usage (Oliveira et al., 2012).

The development of the app involved a user-centred design process, when 35 undergraduate students took part in idea generation sessions to indicate features on the app to suit different cooking scenarios (Oliveira et al., 2015). The suggestions were assessed against an array of strategies from persuasive technology to indicate those suitable and acceptable to be embedded in an application.

Figure 5 shows opportunities for a system to intervene during the cooking activity and ultimately reduce these temporal tensions. Based on the Service Design Blueprint (Bitner, Ostrom, \& Morgan, 2008), this diagram includes the timeline, the physical evidence and inputs, the visible user actions, the 'checkpoints' and also the backstage actions that could be performed by the cooking application (in blue boxes). The roles of the user and a cooking agent are interrelated in order to produce a more optimal process, aiming at energy saving, shorter cooking time, food quality, less effort and reduced temporal tensions. 


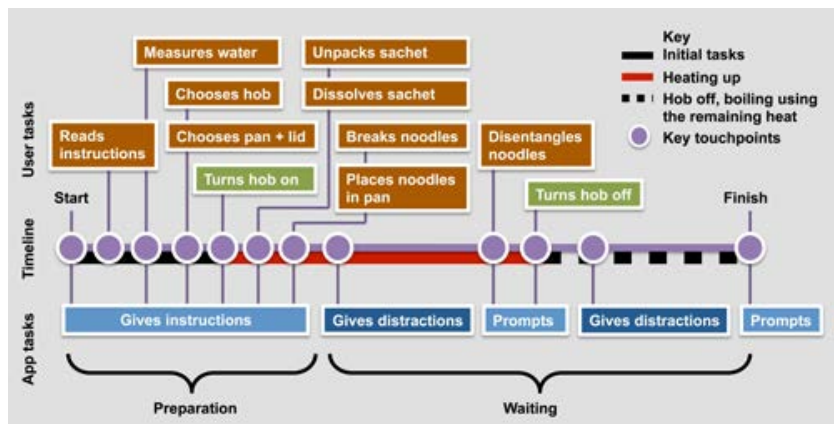

Figure 5 - Preparation and waiting phases showing user and app tasks

From examples of common uses of persuasive technologies as tools (Fogg, 2003; Oinas-Kukkonen \& Harjumaa, 2009), it was possible to select strategies to be embedded within an intervention intended to influence individual behaviours whilst cooking. The selected techniques are listed below and shown on Figure 7, followed by the intervention design strategy used:

- Tailoring is a strategy present when a system uses persuasion through customization. The system can also allow personalization of the outcomes through a set of options, which cause modifications to the processes. By providing options the system can make the user feel more in control of the process, which increases acceptance. The initial interface of the application provided the user with options to select the desired final outcome in relation to the consistency (soft, medium, al dente), the amount of water (soup, wet, sticky) and the time for cooking (slow cook, regular, quick). By selecting their preferred method and outcome, a higher chance of adherence to the energy saving techniques (and consequently success in energy saving) was expected, since participants believe they will obtain the intended results.

- Tunnelling was embedded into the app in order to provide the instructions in steps, consequently preventing users from rushing into the cooking procedure. By providing a sequence of steps to prepare a meal, this guided method indicated the path to follow and allowed little room for modification. The users were presented with the instructions progressively as they accomplished each step and then advanced through the 'tunnel'. The instructions contained the regular methods as found on the back of the food packet plus techniques to reduce energy use, including measuring the amount of water, using a small pan and lid, choosing the small hob and turning the heat off before the end of the cooking process.

- Suggestion is present when the system intervenes at the right time, for example by indicating when is a good moment to perform an energy saving action. The app provides information when needed and displays prompts that guide users to spend the right amount of time on each activity.

- Reduction is the use of technology to make activities easier to perform. The app conveys the right procedure to cook a meal efficiently, provides instructions on how to control the appliances, times the process and prompts users to perform the necessary tasks. By reducing the cognitive load required during the cooking activity, it makes the wait feel more reasonable and reduces the focus on waiting time.

- Entertainment was introduced to provide cognitive engagement (Agarwal \& Karahanna, 2000), foster flow (Csikszentmihalyi, 2000) and consequently reduce the temporal tensions during waiting. Although entertainment is not one of the persuasive tools described by the literature, it was added here as a strategy to distract users from the temptation of using more energy to speed up the process. User concerns that turning the heat off towards the end of the process would increase cooking time were placated by an entertainment strategy that was designed specifically to make users less worried about the activity and let the food finish cooking in an energy efficient way. The app embedded YouTube videos with the approximate duration necessary to bring the water to boil and finish cooking the noodles. 


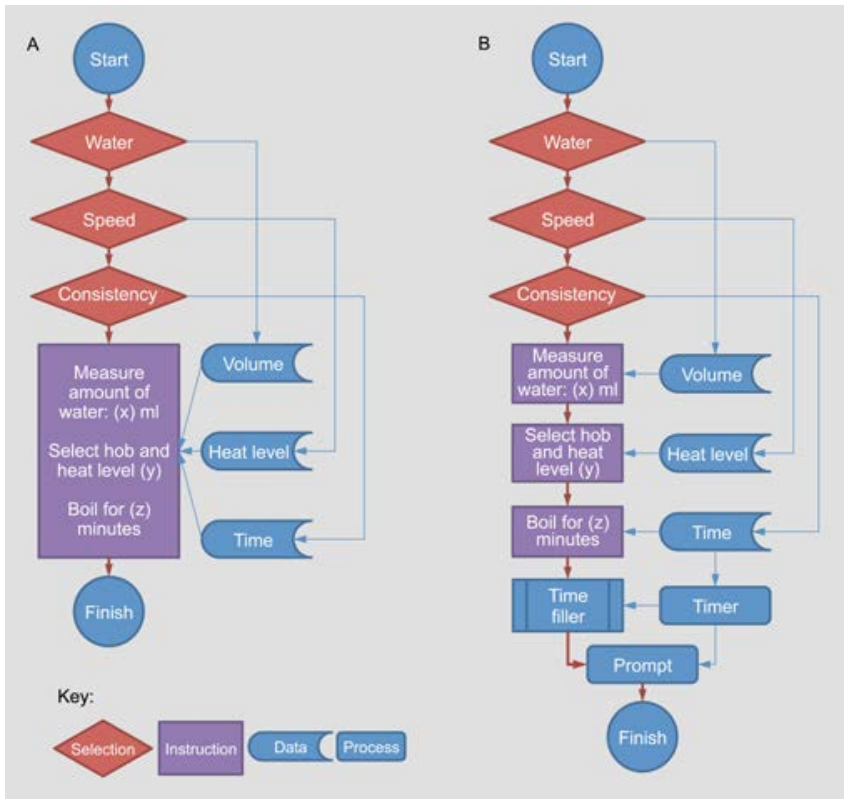

Figure 6 - Diagram of the app used during trial A (control) and B (experimental condition)

Figure 6 presents the structure of the application as a schematic diagram. It indicates the selection stages (diamonds) where the user inputs their preferences. These data are stored by the system and shown on subsequent screens displaying the tailored instructions. Version A (left) contains tailoring strategies embedded but neither time manipulation to reduce temporal tensions nor timers and prompts to facilitate control of the length of the process. Version B of the app (right) has the tailored information in separated screens, and the tunnelling aspect of the persuasive application is shown in red arrows. These steps intend to make users dedicate more time to the preparation and not feel anxious to rush into cooking. The content of the text was, wherever possible, the same as the version A. One added feature during this step is the countdown timer as the reduction strategy. The system counts, display the time and alert the user (suggestion) at the end of the process. One parallel activity is the entertainment strategy. The user has time fillers as cognitive engagement promoting flow, with the intention to reduce boredom when waiting for the food to be ready.

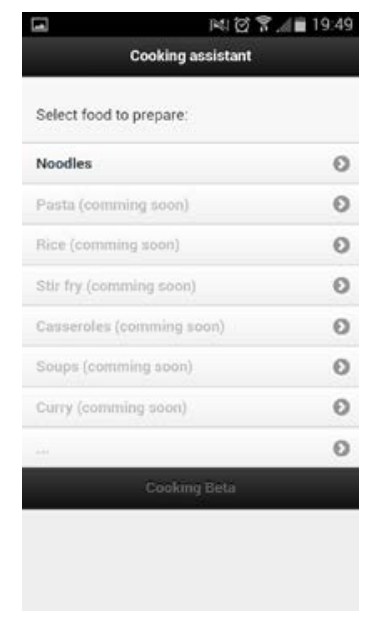

a - Initial screen - other options greyed out indicating that they were disabled on the current prototype

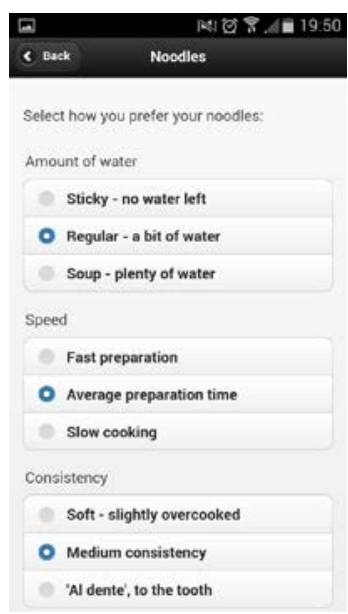

b - Tailoring - radio buttons for the user to select the desired outcomes
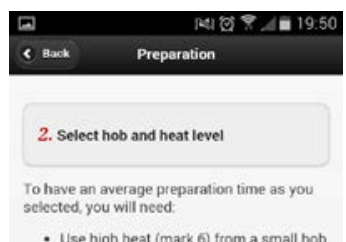

- Use high heat (mark 6) from a small hob : Place the pan on the hob and tum it on
Dissolve the content of the sachet in the

Wotcr the content of the sachet in

- preak the nood the wate
Place the lid

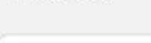

0 Done!
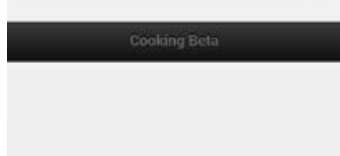

c - Tunnelling and suggestion partial instructions to be followed at this step
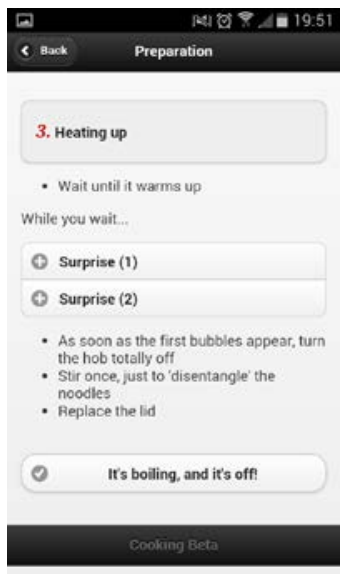

d - Tunnelling and suggestion - another screen/step displays the following group of instructions 


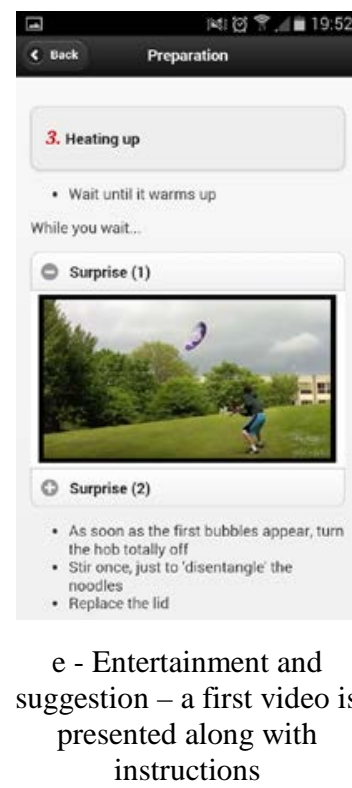

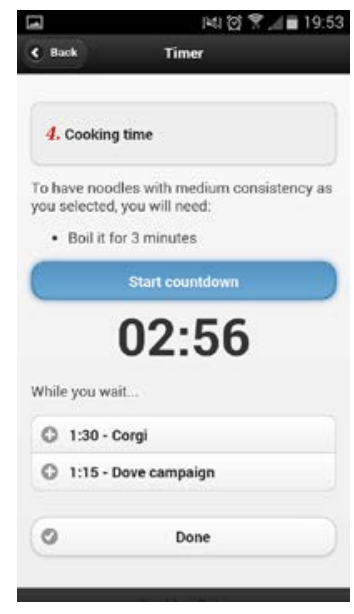

$\mathrm{f}$ - Reduction and suggestion the countdown timer is started along with instructions

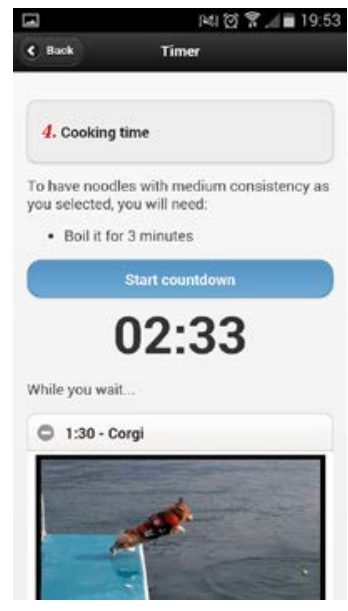

g - Entertainment - More videos are made available until the approximate cooking time is completed

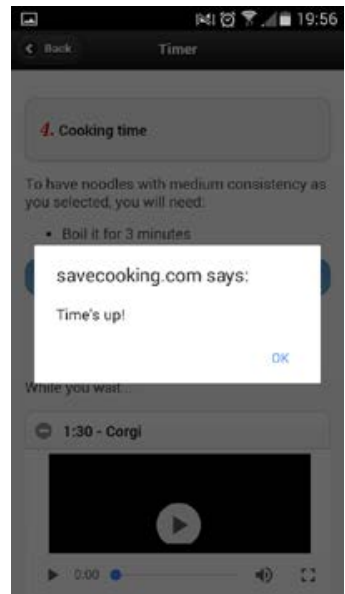

$\mathrm{h}$ - Reduction - one alert prompts the user at the end of the cooking time

Figure 7 - Examples of screens used on the experimental version of the FlowCook app (version B). The control version (A) had only screens a, b and c, with all instructions as bullet points in one single screen (c)

\section{RESULTS}

Data from the observations, scales and interviews performed during this study are presented in this section. With this information it was possible to compare participants' behaviours during trials A and B, and also make some inferences about how effective the app was in changing these behaviours. Results indicate the success of the app in attempting to create engagement with the instructions for better preparation of the cooking process and also in the attempt to reduce the level of boredom during waiting via time-based approaches.

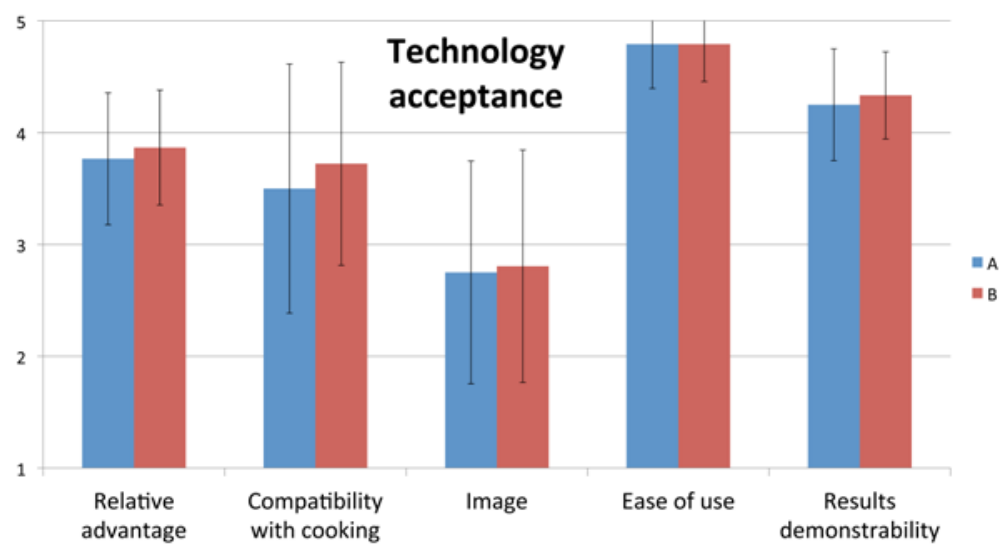

Figure 8 - Technology acceptance measurement - Means and standard deviation

Responses to the rating scales were aggregated to generate an overall score for each construct. The data gathered from these instruments provided means of comparison between both versions of the app used during this study. Figure 8 presents the mean values gathered from the rating scales completed after both trials. It suggests that the acceptance of app tended to increase slightly from app A to B in almost all measurements (although t-test analysis of the paired samples indicated that the difference between tests is non-significant $(p=.074))$. The mean value of 'relative advantage' increased by $3 \%$, 'compatibility with cooking' by $6 \%$ and both the 'image' and 'results demonstrability' by $2 \%$. Ease of use remained the same at a high 4.79 average on a 5-point scale.

Figure 9 presents mean values of measurements of Flow. It suggests a trend towards general improvements from the version A to B of the mobile app (although the difference between tests was non-significant $(p=.223)$ ). The 'paradox of 
control' stayed at a high 4.54 on a 5-item scale, in both phases of the study. The 'autotelic experience' increased by $2 \%$ on average. The other individual constructs of flow presented noticeable improvement. The 'concentration on the task' increased 9\%, and 'immersion' improved by $11 \%$ on the experimental version featuring the persuasive strategies and time perception manipulation. These results suggest enhanced engagement experienced during the interaction with the version B of the app.

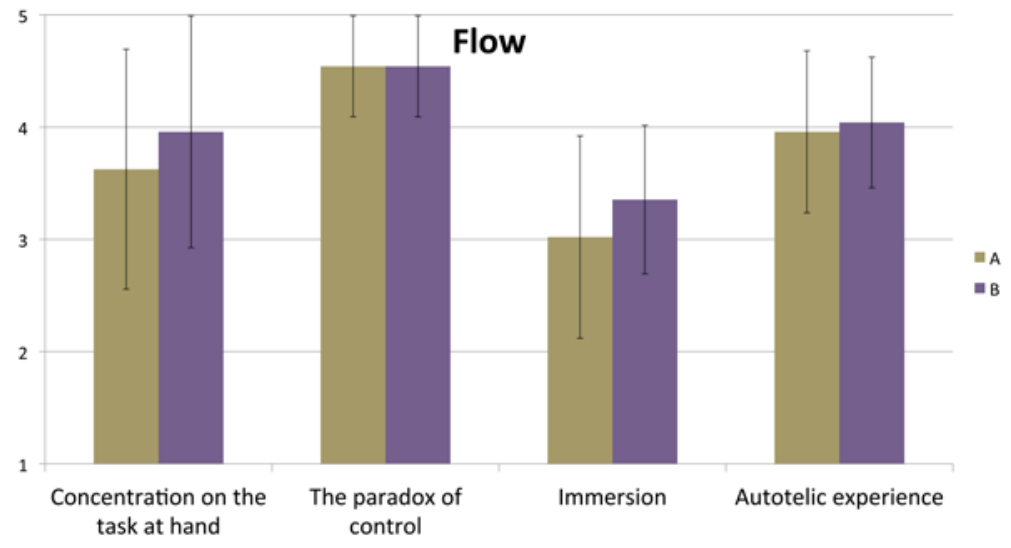

Figure 9 - Flow measurement - means and standard deviation

\subsection{Energy use}

The mean values of energy usage for study A and B were 119.6 and 111.4 Watts hour, with a standard deviation of 39.6 and 34.7 respectively (Figure 10). The reduction of mean consumption from the simpler version of the app to the one featuring the manipulation of time perceptions was 8 Watts hour, or 6.7\%. The energy use data from the 12 participants did not have a normal distribution, therefore a Wilcoxon Signed Rank Test was performed. Matching each pair of observations indicated that seven participants reduced their energy use from app A to B, whereas five increased. To sum up, a Wilcoxon Signed Ranks Test revealed a non-statistically significant reduction in energy usage when using the app $\mathrm{B}, \mathrm{z}=-1.100, p=.271$. The median score on energy usage decreased from trial $\mathrm{A}(\mathrm{Md}=118.5 \mathrm{Wh})$ to trial $\mathrm{B}(\mathrm{Md}=$ $100.5 \mathrm{Wh}$ ). It is understood that the energy data may have been influenced by factors other than the manipulation of time perceptions. These issues will be explored further in the discussion section.

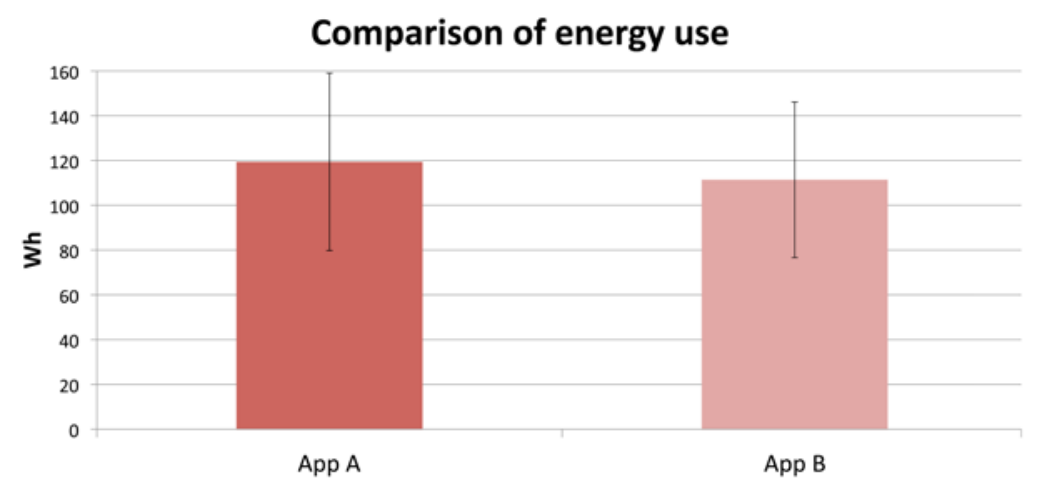

Figure 10 - Comparison of energy use - app A and B - Means and Standard deviations

\subsection{Analysis and feedback on the app}

During the post-experience semi-structured interviews students were asked to comment on the different aspects of the interaction. Questions explored participants’ opinions in order to rate the time perception manipulation and persuasive strategies embedded in the app. Their feedback, separated by persuasive strategy, is explored below.

\subsubsection{Tailoring}

Both versions of the app gave the opportunity for the user to select the desired outcome. This feature was rated as positive by all students. Participant 2 evaluated the customization as positive "because you're more likely to get what you 
like, if you choose what you want, as opposed of having a generic cooking guide". Similarly, participant 7 said that "it's quite good, because so you can do it so it suits to your taste, because everyone is different".

The app calculated how to achieve the expected results by automatically changing the instructions to suit the selections made at the beginning of the interaction. This relationship was illustrated by participant 7 , who said that s/he felt committed to the procedure "because you gave your options, or how you wanted, then you still feel like, if you follow it, you'll get it how you wanted". Most students felt committed to the procedure and evaluated the guidance generally in a positive way. To follow the steps was shown to be worthwhile for participant 6 , since "the results are what I expected it to be, so the instructions were good". S/he later added that "if I was using my eye with the pan I maybe would put in too much water or too little water. So then it affects how it tastes and how I want noodles or whatever the food".

\subsubsection{Tunnelling}

The version B of the app presented a tunnelling strategy, to guide the user through an ideal cooking process. Most participants' comments are related to the fact that tunnelling makes the process easier: "It's like separated, so once you've done one thing, you then move on to the next thing, rather than being faced with the whole page of instructions. That breaks it up and make it easier" [participant 3]. "I like that, because then you can see what you have done, like, then you can move to the next level once you've done it. Whereas, obviously you could have a list, you might get confused by what stage you actually are" [participant 5].

Understandably, some students did not appreciate tunnelling since it constrained their freedom or prevented them from seeing the whole procedure in advance. Participant 2 preferred a single page of instructions "[b]ecause I think you can read the whole sort of procedure before you do it, whereas the other one you had to, I thought I had to do one step, and then find out what the next step was. But I didn't like that [laughs]”. The same opinion is shared by participant 4: “in some ways I prefer the way it was yesterday, when you have all lined down in front of you, rather than clicks and then you see the next bit”.

\subsubsection{Suggestion}

Students were asked about the content of the app, and how they evaluated the instructions and prompts presented. The fact that the suggestions helped to achieve better results was highlighted by participant 12: “you'll never go wrong in your cooking. Like, everything will be fine". These strategies were also appreciated for how they facilitate the cooking process: "it's easier, you get told what to do, and it's just, yes, a lot more easier than thinking about it yourself" [participant 11].

When asked if s/he would trust the instructions from the app, participant 4 illustrated that the commitment to instructions in general should not be strict, advising users to challenge the guidance when appropriate: "I would trust them, but like I said, you use your instincts, if it doesn't look cooked you wouldn't eat it, for example, would you? It's like satnav, you still, like these people who use a satnav and drive into the sea. It's like, oh, hang on a minute, you need a bit of common sense as well, don't you?"

\subsubsection{Reduction}

One of the strategies embedded in the experimental version of the app was a countdown followed by an alert, reducing the necessary mental load involved with keeping track of the duration of the cooking activity. All participants mentioned that these resources were positive. For example, participant 3 said that "that was good. And it came up when it was done so even if you aren't looking it still pop up saying that it's done”. The concept of reduction is clearly illustrated by this quote from participant 9: "it's very simple, because normally I use my watch and it's quite a lot of effort, because you have to turn the watch on and, like, unlock it, because it's a special runner watch, so it's a lot less effort".

Students mentioned that burning their food is an issue that happens sometimes, mainly due to poor time keeping during cooking. Participant 4 presents an adequate anecdote on the issue of cooking time: "I go into my room when I'm cooking, then I come out and 'oh sh*t I burned it'. Not very often, but just occasionally, I get distracted by a phone call or something."

\subsubsection{Entertainment}

Version B of the app presented short random videos with known lengths for the users as a distraction when waiting for the water to heat up or the noodles to cook. Participant 9 illustrated his engagement and how being entertained can make the time pass quicker: "It's great, because it passes the time a lot quicker, three minutes went like that [snaps his finger], which is good".

Participant 2, who tested the app with the entertainment (B) first then used the simpler (A) version later, stated that s/he missed the videos on the second trial: "I felt like time was dragging, even though it was only three minutes like before". Participant 7 complements: "sometimes it can get a bit boring, when you're sort of just waiting for the food to cook".

Adding evidence to the usefulness of the entertainment when waiting for the food to get ready, participant 7 explains that s/he appreciated the distractions because with the video clips people "don't have to keep stirring it and keep, like, because if I just get bored I just stir it, have a look, move around, I don't know”. Participant 6 verbalised the temporal tension when reporting how s/he felt during both trials: 
I think that yesterday's was a lot better because it broke up a little bit more [referring to version B]. Whereas today obviously it's only one slide or one page so it seems a bit more tedious. I took more time sort of doodling about, that sort of thing. Rather than yesterday you were always engaged in the app, because of the videos and things like that, which was quite good.

\section{DISCUSSION}

Evidence from this study indicated that the experimental version of the app was successful in manipulating the time perceptions during the cooking activity. A tool that helps people to take time to prepare the process according to instructions and pay attention to essential steps can motivate an individual to perform behaviours that result in a reduction in energy use. Likewise, an instrument that helps users keep track of time and minimises boredom during waiting can be beneficial during the cooking process. Providing controlled distractions in the form of embedded entertainment resulted in users feeling less bored when waiting for the food to cook. Users perceived the same time as passing more quickly than during normal cooking, and were therefore less likely to want to speed up the process using more energy than required. This manipulation of time perceptions was implemented via a combination of strategies from persuasive technology, which are discussed below.

'Tailoring' provided the possibility of customizing the results according to users' preferences, in an attempt to increase acceptance of (and adherence to) the intervention. Previous research indicates that having tailored advice on a mobile phone showing tips to save energy at home "was well accepted and effective in supporting electricity conservation behavior" (Gamberini et al., 2012, p. 110). The cooking process, even for quick and simple meals, should account for particular preferences. All participants in this study rated this feature positively. The customization of the cooking process improved adherence to the application, therefore facilitating the delivery of the other strategies that implemented the time perception manipulation. Developments of this app would benefit from further strategies to keep interest otherwise novelty wears off. Those could include game elements comprising different levels, planned progress, challenges, achievements and badges to earn (Anderson, 2011; Koster, 2004). Subsequent interactions with the app would unlock more complex dishes and the user would 'level up' to master other energy saving techniques.

'Tunnelling' guided users through the cooking process making sure all the steps required for an efficient cooking were followed. Most participants appreciated that. Even though tunnelling is one of the most frequent strategies used in persuasive interventions (Torning \& Oinas-Kukkonen, 2009), it is not always accepted. A few of our participants complained that they couldn't see ahead. Tunnelling reduces the freedom during the interaction, and it is understandable that it presents resistance.

'Suggestion' was implemented to provide information at the right time. This research used the capability of technology to convey a message informing a desirable course of action at the right time and place. The strategy of suggestion is linked to the principle of Kairos, meaning the right or opportune moment (Fogg, 2003; Oinas-Kukkonen \& Harjumaa, 2009). Participants mentioned that they appreciated the instructions, that it was convenient to have these during the cooking process and that they contributed to a better quality of food in the end.

The 'reduction' strategy embedded in the app included attributing to the mobile device the task of timing the process, minimizing the necessary mental load involved with the cooking activity. Participants in a previous study seldom used a timer when cooking, usually resulting in a longer preparation time than necessary (Oliveira et al., 2012). This strategy was implemented during this study via countdown timers and prompts indicating the end of the cooking time. Most participants managed to turn off the hob at the ideal time to promote energy saving, and none of the students evaluated this strategy negatively. Additional advantages include reduction in fire risk.

'Entertainment' was one of the strategies implemented to reduce the temporal tensions observed and reported in previous research. The presence of videos in the experimental version of the app engaged users and promoted a cognitive involvement with the app. Participants reported being entertained, which made time pass quickly and this is consistent with the notion that 'time flies when you are having fun' - also highlighted by previous research (Agarwal \& Karahanna, 2000). When participants tested the control version of the app without the strategies to minimize temporal tensions, they reported the perception that time was 'dragging', corroborating the adage that says 'a watched pot never boils' (Flaherty, 2000). It appears that the app designed for the experimental condition did manage to fulfil the objective of reducing boredom when waiting during the cooking process.

The success of the entertainment interventions relies on engaging content being supplied - drawing attention to poor content is likely to increase temporal tensions. In this study the content was selected in order to appeal to the sample, with trailers of upcoming films related to a university setting and trending videos. However, in the case of implementing this app (or a similar concept) for a wider population content would need to be bespoke for individuals according to their demographics and personal interests and other distractions such as bite-size gaming could be considered.

Individuals often find their own entertainment to pass the time and alleviate boredom. Participants mentioned that they sometimes have their own distractions whilst waiting during the cooking process. The distractions often occur with the help of other ICTs, as participant 4 states: "people who are cooking generally bring their laptops to the kitchen". Participant 5 adds that "some people in their kitchens might have a TV anyway, so might watch that when they're 
cooking, or might listen to the radio, so just depends". Participant 7 exemplifies other tools to pass the time on the phone itself: "Usually I'd probably just go on Facebook or Twitter or something like that on my phone". However, none mentioned currently having a tool to actively remind them about the cooking time, and therefore a cooking assistant that incorporates time management could be beneficial.

\subsection{Limitations}

The cooking activity raises challenges for the use of technological assistants and electronic interventions. Researchers in HCI usually tend to focus on technological solutions for problems, and sometimes a digital intervention is not suitable or advised (Baumer \& Silberman, 2011). Often, complex issues of sustainability are framed under simple metrics, and technology can be promoted inappropriately as a solution for complex issues (Brynjarsdottir et al., 2012). Grimes and Harper (2008) suggest that human-food interaction is sometimes a celebratory experience, involving uncertainty, experimentation, creativity and fun. People's interaction with food is positive, rich and delightful, and the introduction of corrective technology must be done with care. Sometimes there is not much to be 'fixed': users can enjoy a slow cooking process, for example. They advise that researchers should carefully determine when to introduce technology, to make sure that it is indeed needed. This necessity can provide new ideas about how to design effective technologies "in situations where the introduction of technology does makes sense” (Grimes \& Harper, 2008, p. 474). However, the main objective of this study was not to modify cooking but to provide the platform to test the manipulation of time perceptions and the persuasive strategies to promote sustainable behaviours. One rather simple meal was presented on purpose to avoid complex activities which could make analysis of results problematic. Furthermore, the exercise with the app worked as a learning platform for those inexperienced with cooking and not knowledgeable of energy saving techniques that could be employed.

It was not possible to demonstrate large differences in energy use between the version A and B of the app. This study used a small sample size and a larger number of participants would have increased the power of a statistical comparison between the two conditions. It is also important to consider the Hawthorne effect: people behave differently when they know they are being observed (Kuniavsky, 2003). Participants can be very efficient performing domestic activities if asked to follow specific instructions (Fuss, Bornkessel, Mattern, \& Stamminger, 2011). Therefore our students may have focused on the directions given by both apps knowing that they were being video recorded, hence minimizing any observed differences.

In addition, some participants performed the task differently between trials which impacted on the energy use and introduced experimental variability. Participant 9 reduced the heat and left it on until the end of the cooking instead of switching it off completely half way through the process. S/he reported that the instructions were not very clear: "I thought when it said boil the noodles I thought it meant turn the hob back on to boil the noodles, so that confused me a little bit". Participant 12 had a shorter trial A because s/he turned the larger hob on by mistake instead of the small one.

Finally, some students performed the task differently than recommended by the app during both trials: Participant 4 had long 'on' times because s/he did not measure the amount of water and consequently ended up filling the pan with more water than needed. Participant 7 used hot water from the tap during both trials as a measure to save time: "that's what I usually do, yes. It's quicker than boiling on the hob". Three participants used relatively more energy than the others because they used bigger hobs deliberately, which can be quicker at the expense of more electricity consumption. Participant 1 explains that s/he wanted speed, hence using a big hob: "it's good to, when I'm hungry, to cook quickly. [...] I assume that it cooks quicker, that's why I do it". These remarks underline the importance of minimising time pressure during activities that use energy as a solution to promote sustainable behaviours.

\subsection{Contribution and future work}

As a feasibility study, the intention was to demonstrate the effectiveness of the selected strategies in manipulating perception of time. The analysis of the benefits of this intervention to reduce energy use considered factors other than energy monitoring. The advantages of the strategies implemented could be inducted from other data obtained during this study, namely the qualitative data gathered during the interviews. One review on strategies to evaluate technologies for behaviour change defends that it might be sufficient to assess the success of an intervention via the improvements that the strategies intended to promote (Klasnja, Consolvo, \& Pratt, 2011). If the intention was to reduce temporal tensions, increase engagement and reduce boredom, measuring gains in these aspects can indicate success of the intervention. This research demonstrated how the proposed strategies to minimise temporal tensions were successful as participants had their perceptions of time manipulated during the performance of energy-intense activities.

Further research could be implemented investigating the reduction of temporal tensions with other user groups comprising people of different ages, in different life stages, in other scenarios and with larger sample sizes. Also, it may be possible to implement the manipulation of time perceptions across a wide range of human activities. Peak demand of electricity in the evening is a problem which leads to expensive energy supply solutions (MacKay, 2009). Delaying or anticipating the use of energy can reduce the peak demand, and is also extremely important in the context of renewable generation: "when the wind blows (supply) does not necessarily match when people want to use electricity (demand)" (Higginson, Thomson, \& Bhamra, 2014). Timing and heat conservation can be investigated in other contexts, for example domestic heating systems. Heat lag and set point overshot are common problems which can make occupants 
uncomfortable in the attempt to control domestic temperatures (Coleman et al., 2015). The promotion of flexible consumption that match peak supply will benefit from the reduction of temporal tensions, if it makes people more likely to plan, do in advance or postpone activities that use energy. Evaluation of attempts to modify these temporal tensions in different context of energy use could provide interesting results.

\section{CONCLUSION}

The results presented here made it possible to conclude that the selected persuasive techniques embedded in an HCIbased intervention helped to reduce temporal tensions. These tensions were previously observed during the two distinct phases of cooking, namely preparation, when users did not pay attention to the recommended process which could save energy; and waiting, when users wanted to speed up the process at the cost of extra energy usage. The intervention facilitated the performance of key energy saving behaviours that students were not inclined to do, such as measuring the amount of water or turning the hob off before the end of the cooking time.

According to participants’ evaluations, the strategies implemented to modify the time perceptions worked as intended, minimising the temporal tensions present during the cooking activity. The majority of participants appreciated having the cooking procedure presented in steps with the instructions displayed at the appropriate time, and this increased the likelihood of them paying attention to the procedure. They also enjoyed being entertained when waiting for the food to cook and having timers and prompts that informed them when their food was ready. A few negative aspects were mentioned by participants, such as the reduction of freedom when they could improvise, the limited number of options presented by the app, and the concern that the app could be too distracting during the cooking process. These remarks indicate how the app could be improved, and future versions of the application should address that. As a feasibility study, the aims were largely met and this study concludes that by minimising temporal tensions it is possible to increase the likelihood of adoption of sustainable behaviours and consequently promote energy saving for a simple cooking activity.

\section{CONFLICT OF INTEREST}

The authors declare that no conflicts of interest were observed during the course of this research.

\section{REFERENCES}

Abrahamse, W., Steg, L., Vlek, C., \& Rothengatter, T. (2005). A review of intervention studies aimed at household energy conservation. Journal of Environmental Psychology, 25(3), $273-291$. http://doi.org/10.1016/j.jenvp.2005.08.002

Agarwal, R., \& Karahanna, E. (2000). Time Flies When You're Having Fun: Cognitive Absorption and Beliefs about Information Technology Usage. MIS Quarterly, 24(4), 665. http://doi.org/10.2307/3250951

Amer, T. S., \& Johnson, T. L. (2014). IT Progress Indicators: Sense of Progress, Subjective Sense of Time, User Preference and the Perception of Process Duration. International Journal of Technology and Human Interaction, 10(3), 58-71. http://doi.org/10.4018/ijthi.2014070105

Anderson, S. P. (2011). Seductive interaction design: creating playful, fun, and effective user experiences. New Riders.

Bandura, A. (2001). Social Cognitive Theory of Mass Communication. Media Psychology, 3(3), $265-299$. http://doi.org/10.1207/S1532785XMEP0303_03

Baumer, E. P. S., \& Silberman, M. S. (2011). When the implication is not to design (technology). In Proceedings of the 2011 annual conference on Human factors in computing systems - CHI '11 (p. 2271). New York, New York, USA: ACM Press. http://doi.org/10.1145/1978942.1979275

Bitner, M. J., Ostrom, A. L., \& Morgan, F. N. (2008). Service blueprinting: a practical technique for service innovation. California Management Review, 50(3), 66-95. http://doi.org/10.2307/41166446

Blevis, E. (2007). Sustainable interaction design: invention \& disposal, renewal \& reuse. In Proceedings of the SIGCHI conference on Human factors in computing systems - CHI '07 (p. 503). New York, New York, USA: ACM Press. http://doi.org/10.1145/1240624.1240705

Branaghan, R. J., \& Sanchez, C. a. (2009). Feedback preferences and impressions of waiting. Human Factors, 51(4), 528-538. http://doi.org/10.1177/0018720809345684

Brynjarsdottir, H., Håkansson, M., Pierce, J., Baumer, E., DiSalvo, C., \& Sengers, P. (2012). Sustainably unpersuaded. In Proceedings of the 2012 ACM annual conference on Human Factors in Computing Systems - CHI '12 (p. 947 ). New York, New York, USA: ACM Press. http://doi.org/10.1145/2207676.2208539

Buykx, L., \& Petrie, H. (2011). What Cooks Needs from Multimedia and Textually Enhanced Recipes. In 2011 IEEE International Symposium on Multimedia (pp. 387-392). http://doi.org/10.1109/ISM.2011.70

Chetty, M., Brush, A. J. B., Meyers, B. R., \& Johns, P. (2009). It's not easy being green: understanding home computer power management. In Proceedings of the 27th international conference on Human factors in computing systems CHI 09 (p. 1033). New York, New York, USA: ACM Press. http://doi.org/10.1145/1518701.1518860

Coleman, M., Kane, T., Dimitriou, V., Firth, S. K., Hassan, T., Hauxwell-Baldwin, R., \& Liao, J. (2015). Utilizing smart home data to support the reduction of energy demand from space heating-insights from a UK field study. In 8th International Conference on Energy Efficiency in Domestic Appliances and Lighting (EEDAL) (pp. 1-14). 
Lucerne-Horw, Switzerland. Retrieved from https://dspace.lboro.ac.uk/dspace-jspui/handle/2134/19176

Csikszentmihalyi, M. (2000). Beyond boredom and anxiety. Jossey-Bass.

Csikszentmihalyi, M. (2002). Flow: The classic work on how to achieve happiness. Random House.

Das, T., Subramanian, R., Chakkaravarthi, A., Singh, V., Ali, S. Z., \& Bordoloi, P. K. (2006). Energy conservation in domestic rice cooking. Journal of Food Engineering, 75(2), 156-166.

Davis, F. D. (1989). Perceived Usefulness, Perceived Ease of Use, and User Acceptance of Information Technology. MIS Quarterly, 13(3), 319. http://doi.org/10.2307/249008

Davis, R., Campbell, R., Hildon, Z., Hobbs, L., \& Michie, S. (2014). Theories of behaviour and behaviour change across the social and behavioural sciences: a scoping review. Health Psychology Review, 1-22. http://doi.org/10.1080/17437199.2014.941722

DeMerchant, E. A. (1997). User's Influence on Energy Consumption with Cooking Systems Using Electricity. Virginia Polytechnic Institute and State University. Retrieved from http://hdl.handle.net/10919/29838

DiSalvo, C., Sengers, P., \& Brynjarsdóttir, H. (2010). Mapping the landscape of sustainable HCI. In Proceedings of the 28th international conference on Human factors in computing systems - CHI '10 (p. 1975). New York, New York, USA: ACM Press. http://doi.org/10.1145/1753326.1753625

Fang, X., Zhang, J., \& Chan, S. S. (2013). Development of an Instrument for Studying Flow in Computer Game Play. International Journal of Human-Computer Interaction, 456 29(7), http://doi.org/10.1080/10447318.2012.715991

Ficocelli, M., \& Nejat, G. (2012). The Design of an Interactive Assistive Kitchen System. Assistive Technology, 24(4), 246-258. http://doi.org/10.1080/10400435.2012.659834

Fine, G. A. (1990). Organizational Time: Temporal Demands and the Experience of Work in Restaurant Kitchens. Social Forces, 69(1), 95-114. http://doi.org/10.1093/sf/69.1.95

Fishbein, M., \& Ajzen, I. (2010). Predicting and changing behavior. Taylor \& Francis.

Flaherty, M. G. (2000). A watched pot: How we experience time. NYU Press.

Flaherty, M. G. (2003). Time Work: Customizing Temporal Experience. Social Psychology Quarterly, 66(1), 17 - 33. http://doi.org/10.2307/3090138

Fogg, B. J. (2003). Persuasive Technology: Using Computers to Change What We Think and Do. USA: Morgan Kaufman: SF, CA.

Fraisse, P. (1963). The psychology of time. Greenwood Pub Group.

Fuss, N., Bornkessel, S., Mattern, T., \& Stamminger, R. (2011). Are resource savings in manual dishwashing possible? Consumers applying Best Practice Tips. International Journal of Consumer Studies, 35(2), 194-200. http://doi.org/10.1111/j.1470-6431.2010.00972.x

Gable, P. a, \& Poole, B. D. (2012). Time Flies When You're Having Approach-Motivated Fun: Effects of Motivational Intensity on Time Perception. Psychological Science, 23(8), 879-886. http://doi.org/10.1177/0956797611435817

Gamberini, L., Spagnolli, A., Corradi, N., Jacucci, G., Tusa, G., Mikkola, T., ... Hoggan, E. (2012). Tailoring Feedback to Users' Actions in a Persuasive Game for Household Electricity Conservation. In Lecture Notes in Computer Science (including subseries Lecture Notes in Artificial Intelligence and Lecture Notes in Bioinformatics) (Vol. 7284 LNCS, pp. 100-111). Linköping, Sweden. http://doi.org/10.1007/978-3-642-31037-9_9

Giroux, S., Bauchet, J., Pigot, H., Lussier-Desrochers, D., \& Lachappelle, Y. (2008). Pervasive behavior tracking for cognitive assistance. In Proceedings of the 1st ACM international conference on PErvasive Technologies Related to Assistive Environments - PETRA '08 (p. 1). New York, New York, USA: ACM Press. http://doi.org/10.1145/1389586.1389684

Goodman, E. (2009). Three environmental discourses in human-computer interaction. In Proceedings of the 27th international conference extended abstracts on Human factors in computing systems - CHI EA '09 (p. 2535). New York, New York, USA: ACM Press. http://doi.org/10.1145/1520340.1520358

Grimes, A., \& Harper, R. (2008). Celebratory technology. In Proceeding of the twenty-sixth annual CHI conference on Human factors in computing systems - CHI '08 (p. 467). New York, New York, USA: ACM Press. http://doi.org/10.1145/1357054.1357130

Hallnäs, L., \& Redström, J. (2001). Slow Technology - Designing for Reflection. Personal and Ubiquitous Computing, 5(3), 201-212. http://doi.org/10.1007/PL00000019

Hamada, R., Okabe, J., Ide, I., Satoh, S., Sakai, S., \& Tanaka, H. (2005). Cooking navi. In Proceedings of the 13th annual ACM international conference on Multimedia - MULTIMEDIA '05 (p. 371). New York, New York, USA: ACM Press. http://doi.org/10.1145/1101149.1101228

Harrison, C., Yeo, Z., \& Hudson, S. E. (2010). Faster Progress Bars : Manipulating Perceived Duration with Visual Augmentations. CHI '10 Proceedings of the SIGCHI Conference on Human Factors in Computing Systems, 15451548. http://doi.org/10.1145/1753326.1753556

Higginson, S., Thomson, M., \& Bhamra, T. (2014). "For the times they are a-changin”: the impact of shifting energy-use practices in time and space. Local Environment, 19(5), 520-538. http://doi.org/10.1080/13549839.2013.802459

Hilty, L., \& Lohmann, W. (2013). An annotated bibliography of conceptual frameworks in ICT for sustainability. ICT4S. Retrieved from http://2013.ict4s.org/wp-content/uploads/2013_Hilty_Lohmann_Annotated_Bibliography_ Conceptual_Frameworks_ICT_for_Sustainability.pdf 
Holubar, J. (1961). The Sense of Time: An Electrophysiological Study of its Mechanisms in Man. USA: M.I.T. Press.

Huang, C.-C., \& Stolterman, E. (2011). Temporality in Interaction Design. Proceedings of the 2011 Conference on Designing Pleasurable Products and Interfaces, (c), 62:1-62:8. http://doi.org/10.1145/2347504.2347572

Huang, E. M. (2011). Building outwards from sustainable HCI. Interactions, 18(3), 14. http://doi.org/10.1145/1962438.1962444

Hupfeld, A., \& Rodden, T. (2012). Laying the table for HCI. Proceedings of the 2012 ACM Annual Conference on Human Factors in Computing Systems - CHI '12, 119. http://doi.org/10.1145/2207676.2207694

Hurter, C., Girouard, A., Riche, N., \& Plaisant, C. (2011). Active progress bars: facilitating the switch to temporary activities. In Proceedings of the 2011 annual conference extended abstracts on Human factors in computing systems - CHI EA '11 (p. 1963). New York, New York, USA: ACM Press. http://doi.org/10.1145/1979742.1979883

Karppinen, P., Alahaivala, T., Jokelainen, T., Keranen, A.-M., Salonurmi, T., \& Oinas-Kukkonen, H. (2014). Flow or No Flow? A Qualitative Study of Health Behavior Change Support System. 2014 47th Hawaii International Conference on System Sciences, 3044-3053. http://doi.org/10.1109/HICSS.2014.379

Klasnja, P., Consolvo, S., \& Pratt, W. (2011). How to evaluate technologies for health behavior change in HCI research. In Proceedings of the 2011 annual conference on Human factors in computing systems - CHI '11 (p. 3063 ). http://doi.org/10.1145/1978942.1979396

Koster, R. (2004). A Theory of Fun for Game Design. O’Reilly Media, Inc.

Kujala, S., Vogel, M., Pohlmeyer, A. E., \& Obrist, M. (2013). Lost in time: the meaning of temporal aspects in user experience. In CHI '13 Extended Abstracts on Human Factors in Computing Systems on - CHI EA '13 (p. 559 ). New York, New York, USA: ACM Press. http://doi.org/10.1145/2468356.2468455

Kuniavsky, M. (2003). Observing the user experience: a practitioner's guide to user research (Vol. 1). USA: Morgan Kaufmann.

Lallemand, C., \& Gronier, G. (2012). Enhancing User eXperience during waiting time in HCI: contributions of cognitive psychology. In Proceedings of the Designing Interactive Systems Conference on - DIS '12 (p. 751). New York, New York, USA: ACM Press. http://doi.org/10.1145/2317956.2318069

Lebrun, Y., Lepreux, S., Haudegond, S., Kolski, C., \& Mandiau, R. (2014). Management of distributed RFID surfaces: A cooking assistant for ambient computing in kitchen. Procedia Computer Science, 32, 21-28. http://doi.org/10.1016/j.procs.2014.05.393

Lee, Y., Chen, A., \& Ilie, V. (2012). Can Online Wait Be Managed? The Effect of Filler Interfaces and Presentation Modes on Perceived Waiting Time Online. Management Information Systems Quarterly, 36(2), 365-394. Retrieved from http://hdl.handle.net/1808/17553

Lewis, J. D., \& Weigert, A. J. (1981). The Structures and Meanings of Social Time. Social Forces, 60(2), $432-462$. http://doi.org/10.1093/sf/60.2.432

Lindley, S., Corish, R., Kosmack Vaara, E., Ferreira, P., \& Simbelis, V. (2013). Changing perspectives of time in HCI. In CHI '13 Extended Abstracts on Human Factors in Computing Systems on - CHI EA '13 (p. 3211). New York, New York, USA: ACM Press. http://doi.org/10.1145/2468356.2479649

Lockton, D., Harrison, D., \& Stanton, N. A. (2010). The Design with Intent Method: A design tool for influencing user behaviour. Applied Ergonomics, 41(3), 382-392. http://doi.org/10.1016/j.apergo.2009.09.001

Lundgren, S. (2013). Toying with time. Proceedings of the SIGCHI Conference on Human Factors in Computing Systems - CHI '13, 1639. http://doi.org/10.1145/2470654.2466217

MacKay, D. J. C. (2009). Sustainable Energy - without the hot air. UIT Cambridge Ltd. Retrieved from www. withouthotair.com

Mennicken, S., Karrer, T., Russell, P., \& Borchers, J. (2010). First-person cooking: a dual-perspective interactive kitchen counter. In Proceedings of the 28th of the international conference extended abstracts on Human factors in computing systems - CHI EA '10 (p. 3403). New York, New York, USA: ACM Press. http://doi.org/10.1145/1753846.1753992

Moore, G. C., \& Benbasat, I. (1991). Development of an Instrument to Measure the Perceptions of Adopting an Information Technology Innovation. Information Systems Research, 2(3), $192-222$. http://doi.org/10.1287/isre.2.3.192

Novak, T. P., Hoffman, D. L., \& Yung, Y.-F. (2000). Measuring the Customer Experience in Online Environments: A Structural Modeling Approach. Marketing Science, 19(1), 22-42. http://doi.org/10.1287/mksc.19.1.22.15184

Oberascher, C., Stamminger, R., \& Pakula, C. (2011). Energy efficiency in daily food preparation. International Journal of Consumer Studies, 35(2), 201-211. http://doi.org/10.1111/j.1470-6431.2010.00963.x

Oinas-Kukkonen, H. (2013). A foundation for the study of behavior change support systems. Personal and Ubiquitous Computing, 17(6), 1223-1235. http://doi.org/10.1007/s00779-012-0591-5

Oinas-Kukkonen, H., \& Harjumaa, M. (2009). Persuasive Systems Design: Key Issues, Process Model, and System Features. Communications of the Association for Information Systems, 24(28), 485-500. Retrieved from http://aisel.aisnet.org/cais/vol24/iss1/28

Oliveira, L., Maguire, M., Mitchell, V., \& May, A. (2015). Scenario analysis as a tool for informing the design of behaviour change interventions. In A. Marcus (Ed.), Design, User Experience, and Usability: Design Discourse; 
4th International Conference, DUXU 2015 (pp. 535-547). Los Angeles, CA: Springer International Publishing. http://doi.org/10.1007/978-3-319-20886-2_50

Oliveira, L., Mitchell, V., \& Badni, K. (2011). Understanding Cooking Behaviours to Design Energy Saving Interventions. In S. T. Chiang \& F. P. Moran (Eds.), Buildings Don't Use Energy, People Do? - Research students conference on domestic energy use and CO2 emissions in existing dwellings (pp. 97-106). University of Bath. Retrieved from https://dspace.lboro.ac.uk/dspace-jspui/handle/2134/9249

Oliveira, L., Mitchell, V., \& Badni, K. (2012). Cooking behaviours: a user observation study to understand energy use and motivate savings. Work (Reading, Mass.), 41 Suppl 1, 2122-8. http://doi.org/10.3233/WOR-2012-1016-2122

Oulasvirta, A., Tamminen, S., Roto, V., \& Kuorelahti, J. (2005). Interaction in 4-second bursts: the fragmented nature of attentional resources in mobile HCI. In Proceedings of the SIGCHI conference on Human factors in computing systems - CHI '05 (p. 919). New York, New York, USA: ACM Press. http://doi.org/10.1145/1054972.1055101

Palay, J., \& Newman, M. (2009). SuChef: an in-kitchen display to assist with “everyday” cooking. In Proceedings of the 27th international conference extended abstracts on Human factors in computing systems - CHI EA '09 (p. 3973 ). New York, New York, USA: ACM Press. http://doi.org/10.1145/1520340.1520603

Pilke, E. M. (2004). Flow experiences in information technology use. International Journal of Human Computer Studies, 61(3), 347-357. http://doi.org/10.1016/j.ijhcs.2004.01.004

Sato, A., Watanabe, K., \& Rekimoto, J. (2014). MimiCook : A Cooking Assistant System with Situated Guidance. In 8th International Conference on Tangible, Embedded and Embodied Interaction - Tei 2014 (pp. 121-124). Munich, Germany. http://doi.org/10.1145/2540930.2540952

Seow, S. C. (2008). Designing and Engineering Time: The Psychology of Time Perception in Software. Boston, MA, USA: Addison-Wesley Professional.

Silberman, M. S., \& Tomlinson, B. (2010). Toward an ecological sensibility: tools for evaluating sustainable HCI. In Proceedings of the 28th of the international conference extended abstracts on Human factors in computing systems - CHI EA '10 (p. 3469). New York, New York, USA: ACM Press. http://doi.org/10.1145/1753846.1754003

Steg, L., \& Vlek, C. (2009). Encouraging pro-environmental behaviour: An integrative review and research agenda. Journal of Environmental Psychology, 29(3), 309-317. http://doi.org/10.1016/j.jenvp.2008.10.004

Tamminen, S., Oulasvirta, A., Toiskallio, K., \& Kankainen, A. (2004). Understanding mobile contexts. Personal and Ubiquitous Computing, 8(2), 135-143. http://doi.org/10.1007/s00779-004-0263-1

Tang, T., \& Bhamra, T. (2012). Putting consumers first in design for sustainable behaviour: a case study of reducing environmental impacts of cold appliance use. International Journal of Sustainable Engineering, 5(4), $288-303$. http://doi.org/10.1080/19397038.2012.685900

Torning, K., \& Oinas-Kukkonen, H. (2009). Persuasive system design: state of the art and future directions. In Proceedings of the 4th International Conference on Persuasive Technology (p. 30). ACM.

Tran, Q. T., Calcaterra, G., \& Mynatt, E. D. (2005). Cook’s Collage: Déjà vu Display for a Home Kitchen. In HomeOriented Informatics and Telematics (pp. 15-32). Springer. Retrieved from https://research.cc.gatech.edu/ecl/publications/cooks-collage-deja-vu-display-home-kitchen

Uriu, D., Namai, M., Tokuhisa, S., Kashiwagi, R., Inami, M., \& Okude, N. (2012). panavi: recipe medium with a sensors-embedded pan for domestic users to master professional culinary arts. In Proceedings of the 2012 ACM annual conference on Human Factors in Computing Systems - CHI '12 (p. 129). New York, New York, USA: ACM Press. http://doi.org/10.1145/2207676.2207695

Vildjiounaite, E., Peltola, J., Mäntyjärvi, J., Tokmakoff, A., Kantorovitch, J., Kyllönen, V., ... Keränen, T. (2011). Designing socially acceptable multimodal interaction in cooking assistants. In Proceedings of the 15th international conference on Intelligent user interfaces - IUI '11 (p. 415). New York, New York, USA: ACM Press. http://doi.org/10.1145/1943403.1943479

Wade, J., Hinnells, M., \& Milne, G. (1995). Cooking Appliances. Domestic Equipment and Carbon Dioxide Emissions. Oxford, UK. Retrieved from http://www.eci.ox.ac.uk/research/energy/downloads/decade2.pdf

Webster, J., Trevino, L. K., \& Ryan, L. (1993). The dimensionality and correlates of flow in human-computer interactions. Computers in Human Behavior, 9(4), 411-426. http://doi.org/10.1016/0747-5632(93)90032-N

Wilson, G. T., Bhamra, T., \& Lilley, D. (2015). The considerations and limitations of feedback as a strategy for behaviour change. International Journal of Sustainable Engineering, 8(3), 186-195. http://doi.org/10.1080/19397038.2015.1006299

Wood, G., \& Newborough, M. (2007). Influencing user behaviour with energy information display systems for intelligent homes. International Journal of Energy Research, 31(1), 56-78. http://doi.org/10.1002/er.1228

Woodruff, A., Hasbrouck, J., \& Augustin, S. (2008). A bright green perspective on sustainable choices. In Proceeding of the twenty-sixth annual CHI conference on Human factors in computing systems - CHI '08 (p. 313). New York, New York, USA: ACM Press. http://doi.org/10.1145/1357054.1357109

Zakay, D., \& Block, R. A. (1997). Temporal Cognition. Current Directions in Psychological Science, 6(1), 12-16. http://doi.org/10.1111/1467-8721.ep11512604 